\title{
PENGARUH PENGGUNAAN APLIKASI PEMBELAJARAN EDMODO TERHADAP MOTIVASI BELAJAR SISWA DI SMK NEGERI 2 PANGKEP
}

\author{
${ }^{1}$ Kamal, ${ }^{2}$ Rego Devilla, ${ }^{3}$ Hasria Alang \\ ${ }^{1}$ SMKN 2 Pangkep, Pangkep, Indonesia \\ ${ }^{2}$ Magister Pendidikan Ekonomi STKIP-PI, Makassar, Indonesia \\ ${ }^{3}$ Pendidikan Biologi STKIP-PI, Makassar, Indonesia
}

*Email Korespondensi: surahmannur1007@gmail.com

\section{INFO ARTIKEL}

Diterima 07 Juli 2021

Dipublikasikan 31 Juli 2021

\begin{abstract}
A BSTRAK
Penelitian ini bertujuan untuk mengetahui pengaruh penggunaan aplikasi pembelajaran edmodo terhadap motivasi belajar siswa di SMK Negeri 2 Pangkep. Penelitian ini menggunakan metode kuantitatif. Populasi dalam penelitian ini Siswa Kelas X di SMKN 2 Pangkep, yakni sebanyak 479 orang siswa. Sampel dalam penelitian ini adalah siswa Kelas X SMKN 2 Pangkep terdiri dari 3 Kelas yaitu X TKR 1, X TKR 2 dan X TKR 3 sebanyak 83 orang siswa. Teknik sampling yang digunakan pada penelitian ini yaitu menggunakan probability sampling, adapun metoda yang digunakan adalah simple random sampling. Simple random sampling dikatakan sederhana karena pengambilan anggota sampel dari populasi dilakukan secara acak tanpa memperhatikan strata yang ada dalam populasi itu.Variabel bebas dalam penelitian ini adalah aplikasi pembelajaran edmodo sedangkan variable terikatnya adalah motivasi belajar siswa. Metode pengumpulan datanya menggunakan metode survey, di mana untuk mendapatkan data berasal dari tempat tertentu yang alamiah (bukan buatan), tetapi peneliti melakukan perlakuan pengumpulan data. Hipotesis diformulasikan dan di uji menggunakan analisis regresi linier sederhana. Hasil penelitian menunjukkan bahwa terdapat pengaruh yang signifikan penggunaan aplikasi pembelajaran edmodo terhadap motivasi belajar siswa kelas X Teknik di SMK Negeri 2 Pangkep Kabupaten Pangkajene dan Kepulauan.
\end{abstract}

Kata Kunci: Aplikasi Pembelajaran Edmodo, Motivasi Belajar Siswa

\section{THE EFFECT OF THE USE OF EDMODO LEARNING APPLICATIONS ON STUDENTS' LEARNING MOTIVATION AT SMK NEGERI 2 PANGKEP}

\begin{abstract}
This study aims to determine the effect of using Edmodo learning applications on students' learning motivation at SMK Negeri 2 Pangkep. This study uses quantitative methods. The population in this study were Class $X$ students at SMKN 2 Pangkep, as many as 479 students. The sample in this study were students of Class X SMKN 2 Pangkep consisting of 3 classes, namely X TKR 1, X TKR 2 and X TKR 3 as many as 83 students. The sampling technique used in this study is using probability sampling, while the method used is simple random sampling. Simple random sampling is said to be simple because the sample members from the population are taken randomly without regard to the existing strata in the population. The independent variable in this study is the Edmodo learning application while the dependent variable is student learning motivation. The data collection method uses a survey method, where to get data from a certain natural place (not artificial), but researchers carry out data collection treatments. The results showed that there was a significant effect of the use of Edmodo learning applications on the learning motivation of class $X$ Engineering students at SMK Negeri 2 Pangkep, Pangkajene Regency and Islands.
\end{abstract}




\section{Pendahuluan}

Motivasi belajar merupakan salah satu faktor yang turut menentukan keefektifan dalam pembelajaran. Seorang peserta didik akan belajar dengan baik apabila ada faktor pendorongnya yaitu motivasi belajar. Peserta didik akan belajar dengan sungguh-sungguh jika memiliki motivasi belajar yang tinggi. Motivasi belajar adalah seluruh daya penggerak di dalam diri siswa yang menimbulkan kegiatan belajar yang menjamin kelangsungan dari kegiatan belajar yang memberikan arah pada kegiatan belajar sehingga tujuan yang dikehendaki oleh subjek belajar itu dapat dicapai (Sardiman A. M, 2007: 75).

Ada banyak faktor yang mempengaruhi motivasi belajar yang dapat dibedakan menjadi dua faktor. Menurut Syamsu Yusuf (2009: 23) motivasi belajar dapat timbul karena faktor internal dan eksternal. Faktor internal yang mempengaruhi motivasi belajar yaitu: (1) Faktor Fisik meliputi nutrisi (gisi), kesehatan, dan fungsi-fungsi fisik (terutama panca indera), (2) Faktor Psikologis, yaitu berhubungan dengan aspek-aspek yang mendorong atau menghambat aktivitas belajar pada siswa. Faktor eksternal (yang berasal dari lingkungan) yang mempengaruhi motivasi belajar meliputi: (1) Faktor Non-Sosial meliputi keadaan udara (cuaca panas atau dingin), waktu (pagi, siang, malam), tempat (sepi, bising, atau kualitas sekolah tempat belajar), sarana dan prasarana atau fasilitas belajar, (2) Faktor Sosial, merupakan faktor manusia (guru, konselor, dan orang tua).

Sehubungan dengan faktor-faktor tersebut, guru sangat berperan dalam meningkatkan motivasi belajar siswa. Hasil pengamatan pada SMK Negeri 2 Pangkep kelas X di Kecamatan Bungoro terlihat bahwa pada saat kegiatan pembelajaran berlangsung siswa tidak memperhatikan materi pelajaran yang dijelaskan bahkan ribut di dalam kelas. Oleh karena itu, guru harus mampu menciptakan pembelajaran yang menarik dan menyenangkan agar siswa memiliki motivasi belajar yang tinggi. Agar siswa termotivasi dan merasa senang dalam mengikuti pembelajaran, maka sangat diperlukan keterampilan-keterampilan guru dalam mengajar sesuai dengan perkembangan zaman dan kemajuan teknologi. Salah satu keterampilan yang harus dimiliki dan dikuasai oleh seorang guru adalah menguasai aplikasi pembelajaran. Adapun aplikasi pembelajaran yang dapat digunakan adalah aplikasi pembelajaran edmodo.

Edmodo adalah platform pembelajaran berbasis jejaring sosial yang diperuntukan untuk guru, murid sekaligus orang tua murid. Edmodo pertama kali dikembangkan pada akhir tahun 2008 oleh Nic Borg dan Jeff O'hara. Edmodo memiliki manfaat yang sangat luas sebagai jaringan sosial antara guru dan murid yang dapat dipantau pula oleh orang tua. Apalagi didukung dengan berbagai fitur canggih yang membuat proses belajar mengajar lebih efektif, efisien, menarik dan terorganisir, seperti misalnya fitur polling, gradebook, quiz, file and links, library, assignment, award badge, dan parent code. Edmodo menawarkan alat komunikasi, kolaborasi, dan pembinaan untuk guru dan sekolah. Jaringan Edmodo memungkinkan guru untuk berbagi konten, mendistribusikan kuis, tugas, dan mengelola komunikasi dengan siswa, kolega, dan orang tua.

Tahun 2014, Edmodo meluncurkan Snapshot yaitu seperangkat alat penilaian untuk mengukur kemajuan siswa pada standar pendidikan. Maret 2015, Noodle menyebut Edmodo sebagai salah satu alat pendidikan daring paling inovatif. Edmodo sangatlah membantu dalam proses pembelajaran. Edmodo menyediakan cara yang aman dan mudah untuk membangun kelas virtual berdasarkan pembagian kelas layaknya di sekolah. Desain tampilan yang dimiliki Edmodo hampir sama dengan desain tampilan Facebook. Dengan Edmodo, guru/dosen dapat mengirim nilai, tugas, maupun kuis untuk siswa/mahasiswa dengan mudah.

Selain proses belajar mengajar antara murid dan guru yang semakin dimudahkan, guru pun dapat saling berdiskusi dengan guru-guru lainnya yang berada di belahan dunia lain, berbagi pengalaman mengajar, dan sebagainya. Dalam penggunaan Edmodo, terdapat beberapa hal yang perlu diperhatikan seperti kode khusus untuk setiap kelas/grup. Jika siswa ingin bergabung pada suatu grup, maka siswa terlebih dahulu mengetahui kode khusus grup tersebut. Kelebihan Edmodo dibandingkan dengan aplikasi 
pembelajaran lainnya adalah mudah untuk digunakan, mendukung preview berbagai jenis format file dan dapat diakses dengan menggunakan komputer, laptop dan gadget berbasis Android OS.

Tujuan dari penelitian ini adalah untuk mengetahui gambaran penggunaan aplikasi pembelajaran edmodo dan pengaruh penggunaan aplikasi pembelajaran edmodo terhadap motivasi belajar siswa di SMK Negeri 2 Pangkep.

\section{Metode Penelitian}

Penelitian ini menggunakan metode kuantitatif dan dilaksanakan sesuai kondisi di lapangan pada saat itu. Waktu penelitian ini dilakukan pada bulan Januari sampai 30 Juni 2021. Pengumpulan data pada penelitian ini menggunakan angka-angka dalam statistic. Metode pengumpulan data menggunakan metode survey untuk mendapatkan data dari tempat tertentu yang alamiah (bukan buatan).

Subyek penelitian ini adalah siswa-siswa teknik Kelas X SMK Negeri 2 Pangkep Kabupaten Pangkajene dan Kepulauan. Peneliti mengumpulkan data dalam situasi yang wajar, langsung apa adanya, tanpa dipengaruhi oleh unsur-unsur lain dari luar lingkungan pembelajaran. Oleh karena itu peneliti berhubungan langsung dengan situasi dan sumber data yang diteliti. Sampel yang digunakan dalam penelitian adalah siswa-siswa kelas X Teknik di SMK Negeri 2 Pangkep Kabupaten Pangkep yang berjumlah 83 orang. Teknik sampling yang digunakan pada penelitian ini yaitu menggunakan probability sampling, adapun metoda yang digunakan adalah simple random sampling. Simple random sampling dikatakan sederhana karena pengambilan anggota sampel dari populasi dilakukan secara acak tanpa memperhatikan strata yang ada dalam populasi itu.

Variabel penelitian ini adalah aplikasi pembelajaran edmodo sebagai variable bebas sedangkan variable terikatnya adalah motivasi belajar siswa.

Metode analisis data dalam penelitian ini berupa data kuantitatif dan data kualitatif. Data diolah dengan menggunakan Regresi Linier Sederhana pada aplikasi SPSS Versi 25 untuk mengetahui skor dan persentase pencapaian siswa. Hasil pengolahan data tersebut kemudian digabungkan dengan jawaban siswa berupa proses pengerjaan soal yang dideskripsikan untuk mengetahui sejauh mana siswa memahami soal-soal dan mengetahui letak kesalahan yang dilakukan siswa pada saat menjawab soal tersebut.

Regresi Linear Sederhana adalah Metode Statistik yang berfungsi untuk menguji sejauh mana hubungan sebab akibat antara Variabel Faktor Penyebab $(X)$ terhadap Variabel Akibatnya. Faktor Penyebab pada umumnya dilambangkan dengan $X$ atau disebut juga dengan Predictor sedangkan Variabel Akibat dilambangkan dengan $Y$ atau disebut juga dengan Response (Dickson kho, 2020).

Model Persamaan Regresi Linear Sederhana adalah seperti berikut ini :

$\mathbf{Y}=\mathbf{a}+\mathbf{b X}$

Dimana :

$Y=$ Variabel Response atau Variabel Akibat (Dependent)

$\mathrm{X}=$ Variabel Predictor atau Variabel Faktor Penyebab (Independent)

$\mathrm{a}=$ konstanta

$\mathrm{b}=$ koefisien regresi (kemiringan); besaran Response yang ditimbulkan oleh Predictor.

Nilai-nilai a dan b dapat dihitung dengan menggunakan Rumus dibawah ini:

$$
\begin{aligned}
& a=\frac{(\Sigma y)\left(\Sigma x^{2}\right)-(\Sigma x)(\Sigma x y)}{n\left(\Sigma x^{2}\right)-(\Sigma x)^{2}} \\
& b=\frac{n(\Sigma x y)-(\Sigma x)(\Sigma y)}{n\left(\Sigma x^{2}\right)-(\Sigma x)^{2}}
\end{aligned}
$$




\section{Hasil dan Pembahasan}

Hasil Penelitian menunjukkan bahwa:

\begin{tabular}{|c|c|c|c|}
\hline \multicolumn{4}{|c|}{ Variables Entered/Removed $^{\mathrm{a}}$} \\
\hline Model & $\begin{array}{c}\text { Variables } \\
\text { Entered }\end{array}$ & $\begin{array}{l}\text { Variables } \\
\text { Removed }\end{array}$ & Method \\
\hline 1 & $\begin{array}{l}\text { Aplikasi } \\
\text { Edmodo }^{b}\end{array}$ & & Enter \\
\hline
\end{tabular}

Gambar I. Hasil Output SPPS Variables Entred/Removed

Tabel di atas menjelaskan bahwa variable bebas dalam penelitian ini adalah aplikasi pembelajaran edmodo sedangkan variable terikatnya adalah motivasi belajar siswa dan metode yang digunakan adalah metode enter.

\begin{tabular}{l|l|r|r|r}
\multicolumn{7}{c}{ Model Summary } \\
Model & $\mathrm{R}$ & R Square & \multicolumn{1}{c}{$\begin{array}{c}\text { Adjusted R } \\
\text { Square }\end{array}$} & $\begin{array}{c}\text { Std. Error of } \\
\text { the Estimate }\end{array}$ \\
\hline 1 & $.392^{\text {a }}$ & .154 & .143 & 8.073 \\
\hline
\end{tabular}

a. Predictors: (Constant), Aplikasi Edmodo

Gambar II. Hasil Output SPPS Model Summary

Tabel Output Model Summary menjelaskan besarnya nilai korelasi atau hubungan (R) yaitu sebesar 0,392. Dari output tersebut diperoleh koefisien determinasi ( $R$ Square) sebesar 0,154 yang mengandung pengertian bahwa pengaruh variable bebas aplikasi pembelajaran edmodo terhadap variable terikat motivasi belajar siswa adalah sebesar $15,4 \%$.

\begin{tabular}{|c|c|c|c|c|c|c|}
\hline \multicolumn{7}{|c|}{ ANOVA $^{a}$} \\
\hline Model & & $\begin{array}{l}\text { Sum of } \\
\text { Squares }\end{array}$ & df & Mean Square & $\mathrm{F}$ & Sig. \\
\hline \multirow[t]{3}{*}{1} & Regression & 958.262 & 1 & 958.262 & 14.702 & $.000^{\mathrm{b}}$ \\
\hline & Residual & 5279.425 & 81 & 65.178 & & \\
\hline & Total & 6237.687 & 82 & & & \\
\hline
\end{tabular}

a. Dependent Variable: Motivasi Belajar

b. Predictors: (Constant), Aplikasi Edmodo

Gambar III. Hasil Output SPPS Anova

Tabel output ANOVA menjelaskan bahwa output nilai $F$ hitung $=14,702$ dengan tingkat signifikansi sebesar $0,000<0,05$, maka model regresi dapat dipakai untuk memprediksi variable motivasi belajar siswa atau dengan kata lain ada pengaruh variable aplikasi pembelajaran edmodo $(X)$ terhadap variable motivasi belajar siswa (Y). 


\begin{tabular}{|c|c|c|c|c|c|c|}
\hline \multicolumn{7}{|c|}{ Coefficients $^{a}$} \\
\hline & & \multicolumn{2}{|c|}{ Unstandardized Coefficients } & \multirow{2}{*}{$\begin{array}{c}\text { Standardized } \\
\text { Coefficients } \\
\text { Beta }\end{array}$} & \multirow[b]{2}{*}{$\mathrm{t}$} & \multirow[b]{2}{*}{ Sig. } \\
\hline & & $\mathrm{B}$ & Std. Error & & & \\
\hline \multirow[t]{2}{*}{1} & (Constant) & 62.818 & 10.971 & & 5.726 & .000 \\
\hline & Aplikasi Edmodo & .416 & .108 & .392 & 3.834 & .000 \\
\hline
\end{tabular}

a. Dependent Variable: Motivasi Belajar

Gambar IV. Hasil Output SPPS Coefficients

Tabel Coefficients di atas menjelaskan bahwa diketahui nilai Constant (a) sebesar 62,818, sedangkan nilai variable aplikasi pembelajaran edmodo (b/koefisien regresi) sebesar 0,416 , sehingga persamaan regresinya dapat ditulis :

$\mathrm{Y}=\mathrm{a}+\mathrm{bX}$

$Y=62,818+0,416 X$

Persamaan tersebut dapat diterjemahkan :

- Konstanta sebesar 62,818 , mengandung arti bahwa nilai konsisten ariabel motivasi belajar siswa adalah sebesar 62,818.

- Koefisien regresi $X$ sebesar 0,416 menyatakan bahwa setiap penambahan $1 \%$ nilai aplikasi pembelajaran edmodo, maka nilai motivasi belajar siswa bertambah sebesar 0,416. Koefisien regresi tersebut bernilai positif, sehingga dapat dikatakan bahwa arah pengaruh variable $X$ terhadap $Y$ adalah positif.

- Berdasarkan nilai signifikansi dari table Coefficients diperoleh nilai signifikansi sebesar 0,000<0,05, sehingga dapat disimpulkan bahwa variable aplikasi pembelajaran edmodo $(X)$ berpengaruh terhadap variable motivasi belajar siswa (Y).

- Berdasarkan nilai $t$ : diketahui nilai thitung sebesar 3,834 > ttabel, sehingga dapat disimpulkan bahwa variable aplikasi pembelajaran edmodo $(\mathrm{X})$ berpengaruh terhadap variable motivasi belajar siswa $(\mathrm{Y})$.

ttabel $=(\alpha / 2: \mathrm{n}-\mathrm{k}-1)$

$=(0,05 / 2: 83-1-1)$

$=(0,025: 81)$

$=(\alpha / 2: n-k-1)$

$=3,086$

\section{Kesimpulan}

Berdasarkan hasil penelitian yang diperoleh maka dapat disimpulkan Bahwa penggunaan aplikasi pembelajaran edmodo dapat meningkatkan motivasi belajar siswa di SMK Negeri 2 Pangkep dan Penggunaan aplikasi pembelajaran edmodo mempunyai pengaruh terhadap meningkatnya motivasi belajar siswa SMK Negeri 2 Pangkep.

\section{Referensi}

Husna, Yoga Ayunia Husna. 2020. Pengaruh penerapan aplikasi edmodo terhadap motivasi dan hasil belajar peserta didik kelas XI IPA mata pelajaran SKI di MAN 1 Trenggalek. Tulungagung : Fakultas Tarbiyah dan IImu Keguruan IAIN.

Yulianto dkk, Yoga Hadi. 2018. Pengaruh penerapan sistem pembelajaran online bercorak sosial media dengan menggunakan aplikasi edmodo terhadap motivasi dan hasil belajar siswa. Yogyakarta : Universitas Negeri Yogyakarta. 
Hikmawan, Try. 2018. Pemanfaatan media pembelajaran berbasis edmodo terhadap motivasi belajar siswa sekolah menengah kejuruan. Bandung : Universitas Pendidikan Indonesia.

Nur, Gina Dewi Lestari. 2014. Pembelajaran Vokal Grup Dalam Kegiatan Pembelajaran di SMPN 1

Panumbangan Ciamis. Ciamis : Universitas Pendidikan Indonesia.

Windy, Ines. 2019. Media Pembelajaran Berbasis Edmodo di https://inezwindi.wordpress.com/2019/05/03/media-pembelajaran-berrbasis-edmodo (akses 22 Oktober 2020) 